\title{
CORRESPONDENCIA DEL ARABISTA MALLORQUÍN ARTIGAS CON EL VALENCIANO BORRUL SOBRE HISTORIA ÁRABE VALENCIANA (1828-1829) *
}

Por

MÍKEL DE EPALZA

La correspondencia quie aquí se va a presentar está conservada en Valencia, en la Casa Profesa de la Compañía de Jesús (Papeles Borrull n. ${ }^{\circ} 7$ ). Reviste un cierto interés histórico, tanto por sus protagonistas - Artigas y Borrull - como por la problemática de la historia árabe valenciana por los años 30 del pasado siglo.

E| P. Juan Artigues y Ferragut (su apellido se transformó en Artigas) nació en la villa mallorquina de Sineu, el 8 de diciembre de 1803. Entró en la Compañía de Jesús el 30 de julio de 1817 y estudió en el Colegio de Montesión de los jesuítas de Palma. Muy joven, comenzó sus estudios de lenguas orientales, sobre todo de hebreo y árabe, en el Colegio Imperial de Madrid, regentado por los jesuítas también. En 1824, fue nombrado catedrático de árabe del dicho Colegio Imperial, cargo que ejerció hasta su muerte, asesinado con otros jesuitas de ese importante centro docente de Madrid, el 17 de julio de 1834 (BOVER, 1868, I, 48; LERDO, 1884; REVUELTA, 1976, 205 ).

Su importancia como arabista español está en que representa el nexo académico entre los estudios árabes del siglo XVIII y la nueva generación de arabistas universitarios del XIX. Su papel como profesor de Gayangos, Estébanez Calderón y Carbonero y Sol ha sido destacado por historiadores modernos de los estudios árabes en España (MANZANARES DE CIRRE, 1972, 83-84, 107). El biógrafo de Gayangos (ROCA, 1897, 550) le dedica una importante nota científica, relacionada con el gran arabista erudito español del siglo XIX (VILAR, 1984). El bibliógrafo mallorquín Joaquín María Bover escribió en su biografía (BOVER, 1868): "Su muerte nos privó de ver sus Observaciones sobre varias antigüedades árabes de España, que según nos escribia en carta de 17 de febrero de aquel año /1834/, tenía dispuestas para dar a la estampa" y que actualmente no se sabe si aún permanecen manuscritas en alguna 
biblioteca o archivo. Menéndez y Pelayo llegó a llamarle «el mejor, o más bien, el único arabista que entonces habia en España" (MENÉNDEZ PELAYO, 1882) y su discípulo el escritor $y$ arabista Estébanez Calderón compuso un poema en su honor (ESTÉBANEZ CALDERÓN, 1888).

Con su muerte prematura, a los 31 años, quedó truncada la enseñanza del árabe en la capital de España. Otro jesuita, Raimundo Gasset, le sucedió en su cátedra, para el curso 1834-1835, pero al secularizarse el Colegio Imperial (SIMÓN DIAZ, 1959), dejaron los jesuitas su enseñanza y ya no volvió a aparecer el árabe en sus estudios, como tampoco en la nueva Universidad, trasladada de Alcalá de Henares, hasta unos años más tarde, en 1843. En el Liceo Artístico y Literario se establecieron algunas cátedras en la Sección de Literatura, entre ellas la de Lengua Árabe, a cargo de D. Bernardino Núñez Arenas, en el curso 1838-1839 (ROCA, 1897). Gayangos y Estébanez enseñaron en el Ateneo, suplidos, por la marcha del primero a Londres y del segundo a Sevilla, por Tundidor de Flores, Bermúdez y Creus, hasta que Estébanez volvió a desempeñar esa enseñanza, de 1842 a 1848 (MANZANARES DE CIRRE, 1972, 108-109). Pero los estudios y la enseñanza académica de calidad del árabe tenían que esperar el desarrollo universitario: se creó la cátedra de árabe en la Universidad de Madrid en 1843, para Gayangos, por poco tiempo, pero en Granada desarrollarían los estudios árabes Moreno Nieto, Fernández y González, Eguilaz y Simonet, y en Madrid, Codera y sus colaboradores.

Artigas, erudito positivista, ya hubiera podido completar y depurar la obra de Conde sobre historia árabe de España, que desde su primera aparición en castellano (1820-1821) había tenido y tenía que tener un gran éxito de público erudito o simplemente culto (Artigas se refiere a él en esta correspondencia con Borrull, asi como a su adaptación al francés de Marlés, en 1825, libro que acababa de leer, prestado por un amigol. Tenía la pasión de Conde por la lectura de los textos árabes $y$ por su comprobación por la numismática y la epigrafía monumental.

La relación de Francisco Javier Borrull con los estudios árabes era más distante. De familia valenciana de letrados, había nacido el 3 de diciembre de 1745. Tenía, por tanto, en el momento de nuestra correspondencia, 83 años. Magistrado y político, había representado a Valencia como diputado de las Cortes de Cádiz. Siempre se había distinguido por su amistad con los jesuitas, especialmente por su compatriota de Planes (prov. de Alicante) el P. Juan Andrés (GONZÁLEZ MOLTÓ, 1978), del que escribió una importante nota biográfica, en la que insiste sobre su afecto $v$ el de toda su familia por los jesuitas (BATLLORI, 1966, 516-519). Falleció en Valencia en 1837 (ARDIT).

Es conocida la importancia del P. Andrés en la polémica sobre el origen árabe de la lírica románica (GONZÁLEZ PALENCIA, 1946; MAZZEO, 1965. 155-189). Pero el interés de Borrul por la historia árabe le venía simplemente por su interés por la historia valenciana y sus tradiciones, que había defendido contra las innovaciones, especialmente en el campo jurídico. 
El primer contacto de Borrull con Artigas se debería sencillamente a la imposibilidad que habría en Valencia entonces para descifrar seis monedas árabes, cuyo estudio somete al jesuita y profesor del Colegio Imperial de Madrid. A continuación le enviará su reciente publicación "Discurso sobre la distribución de las aguas del Turia y Tribunal de los Acequieros" (Valencia, 1928), que es además el tema de sus estudios que más se acerca a los estudios arabísticos de su corresponsal en Madrid. Su entusiasmo por el origen árabe de los riegos valencianos y sus instituciones recibe un cauto apoyo del jesuita arabista, que le recomienda que averigüe si hay alguna inscripción monumental que lo confirme. Se compromete en buscar textos de historia árabe valenciana, en árabe, para mejor conocer esa historia, y recomienda a su interlocutor que haga una biografía de los soberanos privativos de la Valencia árabe, a partir de la bibliografía conocida.

Se trata, pues, de un diálogo amable y muy realista, entre un "especialista" y un "aficionado" a los estudios árabes, entre un investigador y un intelectual, entre un arabista encantado del interés por sus temas por parte del personaje local que está entusiasmado por la historia de su tierra y acude al experto para que le amplíe sus conocimientos. En cierta manera, es un buen ejemplo y modelo de "diálogo" entre el universitario y la sociedad culta que le rodea. Esta correspondencia quedó truncada seguramente por la alta edad del magistrado valenciano, aun antes de la trágica muerte del arabista mallorquín.

He aquí, en resumen, el contenido de esta correspondencia, constituida exclusivamente por cartas de Artigas a Borrull.

\section{$28-09-1828$}

Acusa recepción, por medio del P. Calafat, de seis monedas arábigas, cuyas inscripciones descifra y que identifica: $1 .{ }^{a}$ de Abderrahmán IIl de Córdoba; 2. ${ }^{a}$ de Al-Qádir de Valencia; $3 .^{a}$ y $4 .^{a}$ almorávides de Alí lbn Yúsuf Ibn Tashufín; 5. ${ }^{a}$ y $6 .^{a}$ almohades, la última de la ceca de Murcia.

Acusa recepción del primer tomo de la Biblioteca Valenciana. Le anuncia que estudiará a historiadores valencianos, cuyos manuscritos se encuentran probablemente en la biblioteca del Monasterio de San Lorenzo de El Escorial (corregirá más adelante esta noticia).

\section{$16-01-1829$}

Se alegra por la satisfacción de Borrull por las informaciones de la carta anterior y por su iñterés por las antigüedades árabes.

Agradece el envío del texto del discurso de Borrull sobre el origen árabe de los riesgos valencianos (siguiendo a Condel y añade argumentos de verosimilitud a sus hipótesis. Indica que sería interesante hallar inscripciones fundacionales de acequias. 
Se interesa por los cronistas arábigo-valencianos [provecto que realizará, para todos los historiadores de Al-Andalus, el también valenciano Francisco Pons Boigues (PONS BOIGUES, 1898)].

Se preguntará por documentos arábigos en archivos valencianos, de los que ha oido hablar.

Le pide a Borrull que haga una noticia sobre los seis $u$ ocho reyes árabes de Valencia, como se sabe por monedas (describe una de Denia, de 1083).

$13-02-1829$

Por presumir que la anterior carta se ha perdido, repite los temas.

$11-08-1829$

Aprueba la etimología de Guadalabiar, río de los pozos, por ser la principal fuente de agua potable de los valencianos en época árabe (ver confirmación de esta hipótesis en EPALZA, 1980, 1983).

Hará Artigas indagaciones en El Escorial, por si hay manuscritos de cronistas árabes valencianos.

Enviará a Borrull noticias de monedas valencianas correspondientes a los soberanos privativos de Valencia árabe, biografías realizadas por Borrull a petición de Artigas.

04-09-1829

Reconoce que los cronistas árabes valencianos no figuran en el catálogo de Casiri como manuscritos de El Escorial, sino como biobibliografías extraídas de una información sobre un manuscrito de El Escorial, de la Tákmila de Ibn Al-Abbar de Valencia (que sería editado por CODERA, 1888-1889).

Notifica a Borrull que sólo ha encontrado monedas árabes valencianas de "la época de los Régulos» (Taifas), sobre todo los de Toledo-Valencia, y de almorávides que acuñan en Valencia y Denia.

$30-10-1830$

Habla de problemas de historiografía valenciana del siglo XII, con Muhámmad lbn Sad (Ibn Mardanix), y a principios del siglo XIII, con los Banu Hud, antes de la conquista de Jaime I en Valencia $v$ de Fernando III en la Andalucía del Guadalquivir (intento reciente de resolver problemas cronológicos de esa época, en MOLINA LÓPEZ, 1986).

Recomienda a Borrull la lectura de los tres volúmenes de historia árabe de la Península lbérica, por M. Martés, en francés. 
Explica sus trabajos de catalogación de moneda, como instrumento para la historia cronológica de los árabes en la Península.

Esta carta última de Artigas termina con una reflexión muy propia de un «ilustrado» y eclesiástico del siglo XIX: "Pero mientras exista esta frialdad e indiferencia ciertamente vergonzosa, nos veremos precisados a ir a ciegas hasta que el celo de los amantes de la Literatura Arábigo-Hispana produzca buenos efectos».

\section{BIBLIOGRAFIA}

ARDIT: "Borrull y Vilanova”, Gran Enciclopedia de la región valenciana, Valencia, t. II, p. 224

BATLLORI, MIQUEL: La cultura hispano-italiana de los jesuitas expulsos. Españoles-HispanoamericanosFilipinos. 1767-1814, Madrid, 1966.

BOVER, JOAQUIN MARIA: Biblioteca de Escritores Baleares, Palma, 1868.

CODERA, FRANCISCO: Bibliotheca Arabico-Hispana, vols. V-VI, Madrid, 1888-1889.

EPALZA, MIKEL DE: "AI topónimo Guardamar", Revista del Instituto de Estudios Alicantinas, Alicante, 29. 1980, 205-214; 38, 1983, 89-99.

ESTÉBANEZ CALDERON de esta Corte, sobre el estudio de los idiomas orientales”, Obras.., t. IV, Poesías. Madrid, 1888, pp. 9-14.

GONZALEZ MOLTO, ADOLFO: El Abate D. Juan Andrés Morell, Alicante, 1978.

GONZÁLEZ PALENCIA, ÁNGEL: "Posición del P. Arteaga en la polémica sobre música y poesía arábigas», Al-Andalus, Madrid, XI, 1946, 241-245.

LERDO, IGNACIO MARIA: Compendio de las vidas de quince religiosos de la Compañía de jesús sacrílegamente asesinados en Madrid por los sectarios de la impiedad el día 17 de julio de 1834, Madrid, 1884.

MANZANARES DE CIRRE, MANUELA: Arabistas españoles del siglo XIX, Madrid, 1972.

MAZZEO, GUIDO ETTORE: The Abate Juan Andrés, New York, 1965.

MENENDEZ PELAYO, MARCELINO: Historia de los Heterodoxos españoles, Madrid, 1882, lib. VIII, cap. 1.

MOLINA LÓPEZ, EMILIO: "Por una cronología histórica sobre el Sarq Al-Andalus (s. XIII)", Sharq Al-Andalus. Estudios Árabes, Alicante, 3, 1986, 39-55.

PONS BOIGUES, FRANCISCO: Ensayo bio-bibliografico sobre los historiadores y geógrafos arabigo-españoles, Madrid, 1898.

REVUELTA, MANUEL: La exclaustración (1853-1840), Madrid, 1976.

ROCA, PEDRO: "Noticia de la vida y obras de D. Pascual de Gayangos", Revista de Archivos, Bibliotecas Y Museos, Madrid, 1, 1897, 544-565.

SIMÓN DIAZ, JOSÉ: Historia del Colegio Imperial de Madrid, vol. II, Madrid, 1959.

VILAR, JUAN BAUTISTA: "El arabista Pascual de Gayangos en los origenes de la ciencia numismática española: su viaje a París y Londres en 1835n, Sharq Al-Andalus. Estudios Árabes, Alicante, 1, 1984, $161-165$.

- He de agradecer al P. José Martínez de la Escalera S. J., infatigable investigador y profesor de la Universidad Pontificia de Comillas-Madrid, el que pusiera a mi disposición esta documentación que él encontró v el que me proporcionara parte de la bibliografía en este trabajo, especialmente las notas inéditas del P. Medina sobre Artigas. 